\title{
Upgrading the Land Administration System of the Philippines through ICT: A Review of the Land Ti- tling Computerization Program
}

\section{Jovito Jose Katigbak}

De La Salle University, 2401 Taft Ave, Malate, Manila, 1004 Metro Manila; jovito_katigbak04@yahoo.com.ph

Abstract: An effective and efficient land administration system is vital in pursuing national and local development as it ensures security of land tenure, enables citizens to utilise their land, and fosters a peaceful and stable environment. In the Philippines, the Land Registration Authority (LRA) demonstrated its commitment to adopt e-government by launching the Land Titling Computerization Project (LTCP) in 2008. Despite this major step, the viability of the LTCP was put to the test due to a couple of challenges. Thus, this research attempts to describe the opportunities and challenges faced by the LTCP. It uses a descriptive-exploratory method, as it identifies the depth of e-government development in the Philippines with a specific focus on the LTCP. The study finds that the LTCP is currently in the 'enhanced information services' (stage 2) level based on the UN Online Service Index and basic gaps must be addressed via necessary improvements.

Keywords: e-government, e-services, development, land registration, development administration, public policy

\section{Introduction}

An effective and efficient land administration system is a vital element in pursuing national and local development as it ensures security of land tenure, enables citizens to utilise their land and maximize the perceived benefits, and fosters a peaceful and stable environment. Consequently, the emergence of information and communication technologies (ICTs) globally as a mechanism promising efficiency, transparency, equity, and responsiveness in the delivery of public services, has given prominence to the concept of e-government. In the Philippines, the Land Registration Authority (LRA), the agency mandated to implement and protect the Torrens land system of the country, demonstrated its willingness and commitment to adopt e-government by launching the Land Titling Computerization Project (LTCP) in 2008. The LTCP prompted the LRA to computerise all its records and offices nationwide as well as allow the agency to present and deliver electronic services. As of 2015, LTCP is in its fourth phase, with around 92 percent (152 out of 168) of its register of deeds (RD) 
already "live". The cited effort has also enabled the LRA to network with other government agencies including the the Department of Environment and Natural Resources, the Bureau of Internal Revenue, and local government units (Ortile, 2015). Citizens can also expect new services such as the Lot Location Service (LLS), the Title Transaction Alert (TTA), and the Title Trace Back (TTB) (LRA Website, not dated).

Despite these improvements in the country's land title registration system, the viability of the LTCP was put to the test after it provided an unverified list of properties, allegedly owned by a highranking official of the judiciary, as well as low demand for its electronic services. Nonetheless, the LRA's effort to modernise its database and services through the integration of information communication technologies (ICTs) is worth examining. In this sense, this paper seeks to answer the inquiry, "How has the LRA fared in its effort to adopt e-government as embodied by the LTCP? The significance of this study lies in its effort to shed light on the opportunities and challenges faced by the LTCP project and the LRA. More importantly, it draws essential lessons from the best practice in electronic land registration system for the enhancement of the LTCP.

This paper seeks to examine the level of e-government adoption in the country's land title registration system by evaluating the Land Titling Computerization Program (LTCP) of the Land Registration Authority (LRA). Along with the overarching objective, this study also aims to achieve four major purposes. Firstly, it briefly reviews the concept of e-government, stages of e-government, and the current state of e-government adoption in the Philippines. Secondly, this paper describes the mechanisms and components of the LTCP. Next, it considers best practice in the electronic land registration system, specifically Estonia's e-Land Register. Lastly, this study outlines several policy considerations and options for the agency in its effort to continuously develop the country's land title registration system through ICTs.

\section{Literature Review}

\subsection{Overview of E-Government}

New Public Management (NPM) is viewed as representing the governments' response to the growing call for a governance shift from traditional, top-down, and bureaucratic public administration to new, lean, decentralised, and participatory approaches. In particular, stakeholders urged governments to become more mainstream, and promote the values of efficiency, effectiveness, transparency, equity, and responsiveness in the delivery of public services. Osborne and Gaebler (1992) contend that citizens should be treated as "customers" since governments have an obligation to empower rather than serve.

One of the novel reforms that has shown great potential and peril, because of its revolutionising nature, is the application of information and communication technologies (ICTs) by government agencies for better delivery of services. While there is no common definition for e-government, the author would specifically utilise Backus' (2001) definition of e-government which is the use of ICTs by government to enhance its internally focused operations (back-office activities) and externallyfocused services (frontline operations) to facilitate an expeditious, efficient, effective, transparent, 
and accountable process of performing its activities with the public, business, other government agencies, and other sectors. The rationale for adopting e-government include: limited trust and confidence in government, low levels of citizen and business satisfaction with public services, fragmentation and duplication of services, the emergence of the knowledge economy, and the need to spur national competitiveness (World Bank, 2009).

Subsequently, advancing e-government offers tremendous benefits for all countries. In particular, they can expect improved access to the delivery of public services and information, better transparency and engagement with the administration, higher productivity of businesses, citizens, and employees, and a contribution to broader government economic and social outcomes (World Bank, 2009). In contrast, governments should likewise manage various challenges to effectively implement e-government projects. These impediments include: technical barriers, lack of ICT infrastructure, privacy, security, organisational barriers, top management support, resistance to change to electronic ways, collaboration, lack of qualified personnel and training, social barriers, digital divide, culture, and financial barriers (Alshehri\& Drew, not dated).

Jayashree and Marthandan (2010) then underscored that the process of adopting and implementing e-government consists of various stages and/or phases and is continuously evolving. A number of models have been put forward by several researchers and institutions but this study only discusses three models that are internationally recognised and referred to by scholars, practitioners, and policy-makers alike. The first model is crafted by Gartner and others (Baum \& Di Maio, 2000) which has four phases; namely, presence, interaction, transaction, and transformation. Presence is achieved by simply providing information online, while interaction allows basic interactions involving governments, citizens, businesses, and government agencies. Transaction facilitates online transactions such as license renewals and taxes and fees, and transformation focuses on the reengineering of government functions.

The United Nations and American Society for Public Administration's (UN/ASPA) proposed five stages (2001) which are mainly utilised for evaluating the level of e-government maturity of governments. The emerging phase is evidenced by a few independent official sites with limited and basic information, while the enhanced stage has more government sites with dynamic information that is regularly updated. The interactive level enables users to download forms, e-mail authorities, and interact with officials, while the transactional stage allows customers to pay for services or accomplish financial transactions online. The last phase is seamless, which means total integration of e-functions and e-services across administrative boundaries.

The final model pertains to the UN's Online Service Index (OSI) stages which is collectively used as one of the components, along with telecommunication connectivity and human capacity, of the Egovernment Development Index (EgDI) (UNDESA, 2016). The EgDI is a biannual report published by the UN which ranks the performance and overall development of countries in promoting e-government (UNDESA, 2016). There are four phases inparticular; emerging information services, enhanced information services, transactional services, and connected services. The table below contains the stages and their characteristics.

Table 1. Four Stages of Online Service Index (OSI) 


\begin{tabular}{|l|l|}
\hline \multicolumn{1}{|c|}{ Stage } & \multicolumn{1}{c|}{ Characteristics } \\
\hline $\begin{array}{l}\text { 1)Emerging in- } \\
\text { formation ser- } \\
\text { vices }\end{array}$ & $\begin{array}{l}\text { Information on laws, regulations, relevant documents and types of govern- } \\
\text { ment services are available on government websites. Ministries, departments } \\
\text { and other branches of government can be accessed through links found on } \\
\text { the official sites. Information about the national government is updated reg- } \\
\text { ularly and citizens can obtain archived information. }\end{array}$ \\
\hline $\begin{array}{l}\text { 2)Enhanced in- } \\
\text { formation ser- } \\
\text { vices }\end{array}$ & $\begin{array}{l}\text { Official sites enable one-way or simple two-way e-communication between } \\
\text { government and citizens (e.g., downloadable forms). Government websites } \\
\text { are multi-lingual and are equipped with audio and video facilities. Citizens } \\
\text { can submit requests for non-electronic forms or personal information } \\
\text { through a limited number of e-services. }\end{array}$ \\
\hline $\begin{array}{l}\text { 3)Transac- } \\
\text { tional services }\end{array}$ & $\begin{array}{l}\text { Sites can carry out two-way communication between government and citi- } \\
\text { zens. Examples include requesting and receiving inputs on government pol- } \\
\text { icies, regulations, projects, etc. Transactions are successfully completed by } \\
\text { requiring electronic authentication of the citizen's identity. Government web- } \\
\text { sites enable citizens to conduct both financial and non-financial exchanges } \\
\text { such as online payment and filing taxes online, respectively. }\end{array}$ \\
\hline $\begin{array}{l}\text { 4)Connected } \\
\text { services }\end{array}$ & $\begin{array}{l}\text { Official sites have transformed the nature of communication between gov- } \\
\text { ernments and citizens. The former is proactive in requesting feedback and } \\
\text { information from the latter using Web 2.0 and other interactive tools, which } \\
\text { signifies a more empowered citizenry in the decision-making process. There } \\
\text { is full integration across various e-services and e-solutions offered by differ- } \\
\text { ent ministries and departments. Information, data, and knowledge flow } \\
\text { seamlessly among government agencies through integrated applications. } \\
\text { Governments have adopted a citizen-centric approach which is illustrated by } \\
\text { tailor-made e-services and services for specific life cycle events and targeted } \\
\text { groups. }\end{array}$ \\
\hline
\end{tabular}

Source: National Information Society Agency. e-Government of Korea Best Practices. Retrieved 21 February 2017, from http://unpan1.un.org/intradoc/groups/public/documents/UNGC/UNPAN043625.pdf.

\subsection{A Snapshot of E-Government in the Philippines}

The advent of e-government in the country happened as early as 1971 with the establishment of the National Computer Center (NCC). Ona et al. (2012) provided an overview of the Philippine socioeconomic development directions from 1986 to 2010 vis-à-vis national and local ICT strategies and initiatives. In particular, the Aquino administration (1986-1992) aimed to restore democracy to the country and give administrative guidance for the utilisation of ICTs for better delivery of government services (Ona et al., 2012). The Ramos administration (1992-1998) then sought to increase the Philippines' competitiveness on the global stage and promoted the National ICT Plan for the 21st Century (IT21) to transform the country into 'Asia's Knowledge Center,' and become a New Industrialized Country (NIC) bythe early 2000s. The National IT Council (NITC) and the E-Commerce Promotion Council were established to oversee the successful realisation of the said objectives (Ona et al., 2012). Subsequently, the Estrada Administration (1999-2001) made the rural poor its centrepiece project and enacted Republic Act 8792, or the E-Commerce Act, which acknowledges the reliability and validity of online transactions and mandates all government agencies to apply electronic 
means in government transactions. It also launched the e-Philippine Strategy (2000) which highlighted the role of ICT in raising the standard of living of Filipinos (Ona et al., 2012).

Consequently, the Arroyo administration (2001-2010) aimed to sustain the country's economic growth and continuously enhance its global competitiveness. The Philippine Strategic ICT Roadmap 2006 prioritised the empowerment of local communities through ICT, development of ICT infrastructure, and capacity-building efforts focusing on ICT-related skills (Ona et al., 2012). Ona et al. (2012) likewise presented private sector-led ICT industry activities and public sector-led ICT for development initiatives. They concluded that the Philippine ICT for Development (ICT4D) initiatives could be considered "traditional" or disjointed, unsustainable, and short-term oriented. Thus, the country could either retain these approaches or adopt an e-transformation perspective to achieve an ICT-enabled national development (Ona et al., 2012).

Under the Aquino administration (2010-2016), the country witnessed several milestones in terms of national ICT policies and strategies. The Philippine Digital Strategy (2011-2016) envisioned "a digitally empowered, innovative, globally competitive and prosperous society where everyone has reliable, affordable and secure information access in the Philippines." The government also adopted the Philippine E-Government Master Plan (EGMP) (2013-2016) which fosters a-government-wide approach and supports the Medium-Term ICT Harmonization Initiative (MITHI) which promotes government interoperability, collaboration, and shared resources, and the creation of basic national electronic registries (EGPM, not dated). More importantly, the overarching objective of the EGMP is to nurture transformative e-Governance which is vital to achieving the country's development agenda and in fostering good governance (EGPM, not dated). A crucial element of the EGMP is the Integrated Government Philippines (iGovPhil) initiative which seeks to maximize the utilisation of ICT resources through shared ICT infrastructure and services for government agencies. Other critical ICT policies include the Republic Act 10175, or the Cybercrime Prevention Act of 2012, and Republic Act 10844 which created the Department of Information and Communications Technology (DICT).

The Duterte administration (2016-present) recently established the Freedom of Information (FOI) law through Executive Order No. 2 and has developed the EGMP 2.0. The latter document specifies the National Government Portal as the "door" to the E-Government Standard Software Framework. The Government Common Platform then serves as a platform for common data and information which can be accessed, shared, and utilised by participating government agencies. In the $2016 \mathrm{EgDI}$, the Philippines ranked 71 out of 193 countries, advancing from the 95th spot in 2014 which underlines the country's consistent commitment to pursue improvement in terms of e-government development (UNDESA, 2016). It slid down to the 75th place in the 2018 EgDI report (UNDESA, 2018).

\subsection{Revamping the Land Title Registration System: A Focus on LTCP}

As illustrated in the previous discussion, a key sub-sector of e-government in the Philippines that has attracted more focus and thrust is e-services. Since the establishment of the Land Regulation Authority (LRA) in 1903, the land title registration system in the Philippines has been paper-based and manual in nature, which is generally characterised as tedious and expensive. Furthermore, this type of system is viewed to have its fair share of issues such as defective survey plans and technical 
descriptions, land title duplications, data errors, document misplacement, loss of records, existence of fake titles, slow responses to queries, and high vulnerability to graft and corruption as petitioners aim to speed up the registration process by resorting to 'lagay' or under-the-table deals (Ortile, 2015). Moreover, Dealca (2009) notes that the country's land information system is not efficiently managed due to an outdated filing system, inadequate storage capacity, insufficient budget to operate records administration, and lack of trained personnel in records management.

In this regard, the National Economic Development Authority (NEDA) approved in 1997 the information technology-based modernisation programme named 'Land Titling Computerization Project' (LTCP) as a Built-Operate-Own (BOO) undertaking under the Build-Operate-Transfer (BOT) law (Ignacio \& Legaspi, 2000). International public bidding ensued and the contract was awarded to the Strat Com Unisis FF Cruz Comfac (SUFC) Consortium in 2000. President Estrada approved the BOO contract for implementation in 2000 and SUFC tapped the Land Registration Systems, Inc. (LARES) to administer the financing and the day-to-day management of the project. Only in 2008 did the actual implementation of the LTCP begin under the Arroyo administration (Ignacio \& Legaspi, 2000).

Specifically, LTCP has three main objectives: i) issue quick and secure decree of registration, certificate of title, and register documents; ii) provide for a secure, stable and trustworthy record of land ownership and interest; and iii) promote social justice and well-being for national development (LRA website, not dated). LTCP involves the computerisation of the process of registration of voluntary and involuntary transactions affecting land. It also covers the digitisation of the storage, query, and retrieval facilities of the LRA and all the Registries of Deeds (Ignacio \& Legaspi, 2000). The five components of the project to be supplied by LARES are: Computerised Land Titling System (CLTS); conversion/creation/build-up of data of all titles; networking infrastructure of all LRA offices; supply, delivery and commissioning of all IT resource requirements; and provision of IT services (Ignacio \& Legaspi, 2000).

As of 2018, LTCP is in its fourth phase, with around 95 percent (159 out of 168) of its register of deeds (RD) nationwide already "live" or computerised (Ortile, 2018). The LTCP has also digitised the LRA central office and 19 extension offices. Land titles and deeds are inputted and processed through the automated Philippine Land Registration and Information System (PHILARIS) (LRA website). The cited effort has likewise enabled the LRA to network with other government agencies including the Department of Environment and Natural Resources, the Bureau of Internal Revenue, the Home Development Mutual Fund, and local government units to provide services (Ortile, 2015). In addition, it has allowed the agency to offer quick, reliable, secure, and efficient e-services to citizens, such as the Voluntary Titling Standardization Program (VTSP), the Parcel Verification Service (PVS), Anywhere-to-Anywhere (A2A) and the LRA Online Tracking System (LOTS). Citizens can also expect upcoming services which include Cashless Payment Services, the Lot Location Service (LLS), the Title Transaction Alert (TTA), and the Title Trace Back (TTB) (LRA Website, not dated). The LRA website has made available on its website relevant policies, downloadable forms, various requirements, and corresponding fees for the agency's manual and e-services. It likewise provides an e-mail address and mobile number for the queries and concerns of citizens. However, the website has no feedback forms and the contents of several posts are incomplete. 
Ortile (2018) reports that the LTCP has already scanned, encoded, and stored around 25 million land titles and 15 million supporting documents, which was made possible by "full enterprise-wide client-facing and back-end systems". The program also covers an extensive network, comprising the LRA Central Office, Registries of Deeds, LRA Extension Offices, Data Center, and Disaster Recovery Facilities. These IT facilities are managed centrally on $24 \times 7$ basis. More recently, the LRA launched the Online Personal Property Security Registry.

The issues and challenges faced by the LRA during the implementation of LTCP include reports of erroneous land titles issued by LRA, storage of cancelled titles in the database, delays in the release of more expensive titles, and a long period of release of land titles due to the Torrens system, despite the adoption of LTCP. Given the current maturity level of LTCP, it is worth asking: Is there a viable model that the LRA can emulate in its effort to continuously improve the land registration and records system of the Philippines?

\subsection{Learning from the Best: Estonia's e-Land Register}

Estonia is globally recognised for its successful effort in using ICTs to provide better public services and to foster e-governance. In the $2016 \mathrm{EgDI}$, the country ranked 13th and registered 0.8913 in the Online Service Index (OSI), which is regarded as very high (UNDESA, 2016). The two building blocks enabling a digital society in Estonia are the e-Identity (e-ID) and the X-Road. e-ID is the nationwide uniform system for validating a citizen's identity in a digital setting and acts as a mechanism for Estonians to access secure e-services, while the X-Road is the national digital information infrastructure that permits the seamless exchange of data and information by government agencies, citizens, and the private sector among decentralised databases and registers (e-Estonia.com). All eServices solutions were created by the private sector and the Estonian government acted as a rational buyer.

The e-Land Register is one of the many testaments to Estonia's progress in nurturing a digital society. Accordingly, the unique web application has records on cadastral information, encumbrances, restrictions, right of use, and other notations, ownership relations, and mortgage information (e-Estonia.com). It is also connected with other basic registers, the cadastre registry, and the population registry, thereby allowing citizens to accomplish the whole registration procedure online on the one hand, and notaries and other officials to gather specific information from the e-Land Register on the other (Centre for Registers and Information Systems website). As such, the electronic system has brought down the processing time for land transactions from as long as three months to as early as eight days (e-Estonia.com). To avail themselves of the e-service, citizens must create their personal accounts to view land registry documents (free-of-charge), authorise others to view documents, use the digitisation service, and view land property data (paid) (Centre for Registers and Information Systems website). Citizens can then utilise the services through their e-ID or online banking. Data collected from the e-Land Registry have legal power and are presumed correct (Centre for Registers and Information Systems website). The e-Land Register is supported by a geographical information system (GIS) and is directly linked to the X-Road hence enabling the application to provide real-time data to users (e-Estonia.com). 
Indeed, the case of Estonia's e-Land Register is a model worth examining by the Philippine government, specifically for its LTCP. This is because Estonia's electronic land registration system is founded on the X-Road, which is the country's national digital information infrastructure. Given this set-up, the e-Land Register has well-functioning links with other relevant government agencies, thus stimulating efficiency gains and reducing transaction costs for both the government and customers. The goal of the LTCP's infrastructure system is somewhat similar to the Philippine government aims, which is to connect it with other concerned public sector agencies. The backbone of this national IT infrastructure for the government is the Medium-Term ICT Harmonization Initiative (MITHI) under the E-Government Master Plan (EGMP), and the Common Government Platform under the EGMP 2.0. More importantly, the current state of and services offered by the e-Land Register have the same aspirations of the LTCP. Thus, extensive perusal and eventual adoption of the best practices of Estonia's cited programme are paramount policy options for the Philippine government.

\section{Methodology}

This research is classified as descriptive-exploratory. It identifies the depth of e-government development in the Philippines with a specific focus on the Land Titling Computerisation Project (LTCP) of the Land Registration Authority (LRA). This study uses a deductive approach as it utilises the United Nations' OSI stages and their characteristics as the main reference in determining the level of e-government adoption by the LRA. This research mainly utilises a qualitative approach in order to ascertain the extent of the research problem by qualifying the indicators, while supporting them with quantitative data. The main method for data gathering is secondary research which involves review of related literature and content analysis. It utilises secondary resources such as books, journals, news articles, the LRA website, data from research studies, and reports institutions present on their official websites. The study is exploratory as it attempts to evaluate the progress of LTCP in terms of e-government development being undertaken by the LRA.

\section{Discussion}

Despite the remarkable strides achieved by the LRA in terms of e-government adoption through the LTCP, its e-services can still be classified as belonging to stage 2 or enhanced information services. Notably, the LTCP has surpassed phase 1, or emerging information services, through the fulfillment of several criteria. Particularly, information on laws, regulations, relevant documents and types of government services should be available on government websites, according to the UN OSI model. Ministries, departments and other branches of government should similarly be accessible through links found on the official sites. In addition, information about the national government is updated regularly and citizens can obtain archived information.

Correspondingly, LRA's website contains information on the institution's history, mandate, legal foundations and related issuances, officials, and a list of register of deeds (RDs) located in different parts of the country (through a "Branch Finder"). As part of its commitment to exercising transparency, LRA has also published its Management Accountability Report Cards (until 2015), Annual 
Reports (but only until 2012), Budget Reports (until 2015), and Procurement Plan (for Fiscal Year 2017). More importantly, there is available information on the status, objectives, and updates of the LTCP. The official website of the LRA also posted links to the organisation's partner agencies (i.e., DOJ, Pag-IBIG Fund, BIR, DENR, DAR, etc.). However, the information found under these categories is limited and not regularly updated and some of the links do not direct the online user to the archived data. Thus, improvements can still be made in terms of promoting dynamic, comprehensive, and up-to-date information. On the technical configurations of the website, www.LRA.gov.ph is in the English language and does not have audio and video capabilities. Videos on the LRA and the LTCP can instead be found on another site.

Consequently, a programme can be classified under stage 2 of the UN OSI model when official sites facilitate one-way or simple two-way e-communication between government and citizens (e.g. downloadable forms). Requests for non-electronic forms or personal information can likewise be submitted by citizens through a limited number of e-services.

Regarding LRA, its website has a yellow-pages type directory of basic services such as issuance of title on registered land, annotation on title, chattel mortgage registration, cancellation/ release of mortgage, issuance of certified true copies of title, and query/research. Sample forms, requirements, and fees can also be viewed and downloaded over the internet. For e-services, downloadable forms and background information on the Voluntary Title Standardisation Program (VTSP), Parcel Verification Service (PVS), and Anywhere to Anywhere (A2A) facility are accessible over the internet. The LRA Online Tracking System (LOTS) is already operational which allows citizens to be aware of their transaction status with any RD. The agency is likewise in the final stages of crafting new eservices such as the Lot Location Service (LLS) (users can verify the cadastral information and identify errors), Title Transaction Alert (TTA) (SMS notification sent to the titleholder whenever his/her land title is accessed), and Title Trace Back (TTB) (owners can trace the history of their titles). While all of these e-services have reducedwaiting time and made procedures easier and clearer, there is much room for enhancement as the VTSP, PVS, and A2A facility only provide for electronic processes in the initial step (i.e., downloading forms and preparing requirements); citizens would still need to physically access any RD or the LRA Central Office to submit the forms and requirements, pay the corresponding fees, and completely avail themselves of the basic and new services.

Moreover, the LOTS, LLS, and TTA appear to offer services that can be accessed entirely in an electronic manner, but the LRA's e-services can generally be considered as exercising a form of oneway communication. A two-way communication is somewhat reflected in that users can raise their queries and concerns through the e-mail address (customerservice@lra.gov.ph) posted by the agency, as well as via designated mobile numbers, but feedback forms should be made available to citizens.

In summary, the LTCP is currently in the enhanced information services (stage 2) level of the OSIand basic gaps must be addressed via necessary improvements. The LRA acknowledges that much work is to be done, hence the organisation's effort to develop new e-services and further strengthen links with other government agencies. Its initiative of developing a cashless payment system illustrates the LRA's cognizance that the move towards the next stage (transactional services) entails building the capacity of the agency to conduct financial transactions over the internet. 


\section{Conclusion}

The strong call for a new type of development approach was answered by the emergence of New Public Management (NPM) into the mainstream, which promotes the principles of decentralisation, participation, efficiency, transparency, and 'citizens as customers.' E-government can be regarded as one of the innovations brought by NPM, as it enables governments to provide better public services to its citizens and to foster e-governance in the process. In the Philippines, the adoption of egovernment happened as early as the 1970s but progressed slowly from 1986 to 2010 due to traditional and short-sighted perspectives across various administrations (Ona et al., 2012). The Aquino administration (2010-2016) achieved significant milestones in e-government and laid significant foundations for the continuous development of e-government in the country. The next administrations are therefore poised to lift the nation's level of e-government maturity, but transformational and government-wide approaches must be pursued by future leaders.

An area that is critical for raising the standard of living of Filipinos is effective and efficient land administration in an increasingly digital landscape. The Land Titling Computerisation Project (LTCP) has greatly helped the Land Registration Authority (LRA) in moving towards internet-based operations and in offering electronic services to Filipino citizens in an efficient, transparent, and convenient manner. However, it is still low on the scale in terms of its maturity; in fact it is in stage 2 of the OSI which is classified as enhanced information services. The government, specifically the LRA, can (and should) therefore undertake both basic and major improvements to maximize the benefits of the LTCP project and propel the country towards greater heights in terms of e-government development.

With the Philippines being right at the crossroads of e-government development, decision makers and stakeholders should always keep in mind three things: a) advanced e-government countries may serve as an inspiration but are not accurate models for a developing country like the Philippines given its uniqueness; $b$ ) "one time big time" projects are not the solution, due to the fact that mainstreaming e-government is an arduous, dynamic, and non-linear endeavour in an ever-changing world environment; and c) the successful realisation of e-government efforts and initiatives are founded on active participation of all stakeholders and their synergistic and symmetric networks.

\section{Recommendations}

The case of Estonia underlines key lessons for the Philippine government as it seeks to promote egovernment within the country and institute an efficient land records and registration system through ICT adoption. In the short term, the Land Registration Authority (LRA) should be proactive in updating the contents, especially archived information, of its website, as well asmaking www.lra.gov.ph translatable to the Filipino language and having audio and video capabilities. Furthermore, the official site should enable users to submit forms along with the scanned requirements and pay the necessary fees over the internet. The PHILARIS should be made accessible to the public so that users can obtain information and conduct transactions through their secured personal accounts. 
In the medium term, PHILARIS should be linked to other electronic databases (as exemplified by the LRA-BIR collaboration), ala X-Road, to realise free flow of data and information among government agencies. Businesses and citizens should also have the capability to enter the integrated database for specific purposes provided by the law. On the other hand, the government should also establish a nationwide system of uniform electronic identification (ala e-ID) to ensure quick authentication of identity. The role of the private sector in offering e-solutions for the government at a reasonable fee is crucial to successfully attaining the aforementioned initiatives.

In the long term, the Philippine government should strive to build a robust online ecosystem where government agencies enjoy total interoperability and citizens conveniently access tailor-made e-services and complete both non-financial and financial transactions over the internet. As such, the government must rigorously install facilities and technologies all over the Philippines, thereby enabling broadband connectivity. Bridging the digital divide likewise entails capacitating Filipinos with technical and ICT-related skills for basic use of e-services as well as for acquiring ICT-oriented livelihoods. Ultimately, these efforts would result in an empowered citizenry that is actively engaged in the decision-making process and regularly provides feedback to the government as the latter tries to chart the country's course towards a truly digital Philippine society.

While the abovementioned recommendations mainly focus on policy options and considerations, this study likewise seeks to identify areas for future research, especially for scholars and students of Philippine governance in the digital age. Accordingly, subsequent studies may be undertaken to collate and analyse the perspectives and experiences of the general public and target customers in using the services of the Land Titling Computerization Programme (LTCP).A qualitative or quantitative approach, or a combination of both, may be adopted by interested researchers. Further, subsequent research may explore the actual impact of the LTCP on the government's drive towards greater efficiency and transparency through e-government adoption. Lastly, future studies may dwell on the challenges faced and being confronted by the LRA in implementing the LTCP. Key findings may serve as vital reference points for other public sector agencies seeking to modify their services and operations, and to anchor them to dynamic digital systems.

\section{References}

Alshehri, M.\& Drew, S.J. (not dated). E-government principles: implementation, advantages and challenges. Int. J. Electronic Business. Available at http://www98.griffith.edu.au/dspace/bitstream/handle/10072/42703/73445_1.pdf?sequence=1.

Backus, M. (2001). E-governance in developing countries. IICD Research Paper. Retrieved 31 January 2017, from http:/ / www.ftpiicd.org/files/ research/briefs/brief1.pdf.

Basu, S. (2004). E-Government and Developing Countries: An Overview. International Review of Law Computers and Technology Vol. 18 (1), 109-132.

Baum, C. \& Di Maio, A. (2000). Gartner's four phases of e-government model. Retrieved 1 March 2017, from http:/ / www.gartner.com/DisplayDocument?id=317292. 
Center for Democracy and Technology. (2002). E-Government Handbook. Retrieved 23 February 2017, from http://www.cdt.org/egov/handbook/.

Centre for Registers and Information Systems. (not dated). e-Land Register. Retrieved 3 March 2017, from http:/ / www.rik.ee/ en/ e-land-register.

Dealca, R.L. (2009). Initiatives to Improve Land Administration System in the Philippines. Presented at the7th FIG Regional Conference on Spatial Data Serving People: Land Governance and the Environment - Building the Capacity in Hanoi, Vietnam, 19-22 October 2009.

e-Estonia.com. (not dated). Digital Society. Retrieved 3 March 2017, https:// e-estonia.com/thestory/digital-society/.

e-Estonia.com. (not dated). Electronic Land Register. Retrieved 3 March 2017, from https://eestonia.com/component/electronic-land-register/.

Ignacio, C. \& Legaspi, J. (2000). Overview of the Land Titling Computerization Project. Presented at the LTCP Implementation Seminar, 15 September 2000.

Information for Development Program (infoDev)/World Bank. (2009). e-Government Primer. Washington, DC: infoDev/World Bank.

Jayashree, S. \&Marthandan, G. (2010). Government to E-government to E-society. Journal of Applied Sciences, 10 (19), 2205-2210.

Land Registration Authority (LRA). (notdated). Retrieved 1 February 2017, from www.lra.gov.ph.

Ortile, R. (2015). "Updates on the LTCP and the Implementation of the eTitling Standardization Program". Presented at the Policy Dialogue on Effective Regulations for Sustainable Growth. 17 September 2015. Quezon City.

Ortile, R. (2018). "LRA and the Personal Property Security Act". Available at http:/ / rbap.org/wpcontent/uploads/2018/10/Atty.-Ronald-Ortile-Presentation_LRA.pdf.

Layne, K., \& Lee, J. (2001). Developing fully functional E-government: A four stage model. Government Information Quarterly, 18, 122 -136.

Ona, S., Ulit, E. \& Hanna, N. (2012). The Philippines: The Quest for Genuine e-Development. National Strategies to Harness Information Technology: Seeking Transformation in Singapore, Finland, the Philippines, and South Africa. Springer: New York, 153-194.

Osborne, D. and Gaebler, T. (1992).Reinventing Government: How theEntrepreneurial Spirit is Transforming the Public Sector. Addison-Wesley: MA.

Philippine Digital Strategy 2011-2016. Retrieved 2 March 2017, from http://www.dict.gov.ph/wp-content/uploads/2014/06/philippine-digital-strategy-20112015.pdf. 
Philippine E-Government Master Plan (EGMP). Retrieved 2 March 2017, from https:/ / mithiph.files.wordpress.com/2014/01/egmp_final-version.pdf.

United Nations Department of Economic and Social Affairs. (2016). United Nations E-Government Survey 2016, E-Government in Support of Sustainable Development. New York: United Nations. Available at http://workspace.unpan.org/sites/Internet/Documents/UNPAN96407.pdf.

UNDESA. (2018). UN E-Government Knowledgebase. Available at https://publicadministration.un.org/egovkb/en-us/Data/Country-Information/id/134-Philippines.

United Nations Division for Public Economics and Public Administration. (2001). Benchmarking E-government: A Global Perspective - Assessing the Progress of the UN Member States. Retrieved 23 February 2017, from http://pti.nw.dc.us/links/docs/ASPA_UN_egov_survey.pdf.

\begin{abstract}
About the Author
Jovito Jose Katigbak

Mr. Jovito Jose Katigbak is a Foreign Affairs Research Specialist II (FARS) of the Center for International Relations and Strategic Studies (CIRSS) of the Foreign Service Institute (FSI). He undertakes policy-oriented research and analysis on trade and trade-related matters, under the International Organizations section. Mr. Katigbak is currently taking up Master of Arts in Development Policy at the De La Salle University. He graduated Magna Cum Laude in the Consular and Diplomatic Affairs Program of the De La Salle - College of Saint Benilde (DLS-CSB). He has participated in various local and international conferences and seminars focusing on international relations and development. Mr. Katigbak has published articles on ASEAN integration, Philippine trade policy, internet economy, and sustainable development. His areas of interest include political economy, public policy, development, and e-commerce.
\end{abstract}

